REVIEW

\title{
Perioperative hypertension management
}

\author{
Joseph Varon' \\ Paul E Marik ${ }^{2}$ \\ 'The University of Texas Health \\ Science Center at Houston, and The \\ University of Texas Medical Branch \\ at Galveston. St. Luke's Episcopal \\ Hospital/Texas Heart Institute, \\ Houston, TX, USA; '2Department \\ of Pulmonary and Critical Care \\ Medicine, Thomas Jefferson University, \\ Philadelphia, PA, USA
}

\begin{abstract}
Perioperative hypertension is commonly encountered in patients that undergo surgery. While attempts have been made to standardize the method to characterize the intraoperative hemodynamics, these methods still vary widely. In addition, there is a lack of consensus concerning treatment thresholds and appropriate therapeutic targets, making absolute recommendations about treatment difficult. Nevertheless, perioperative hypertension requires careful management. When treatment is necessary, therapy should be individualized for the patient. This paper reviews the pharmacologic agents and strategies commonly used in the management of perioperative hypertension.
\end{abstract}

Keywords: hypertension, hypertensive crises, intraoperative, perioperative, postoperative, surgery

\section{Introduction}

In the United States, it is that estimated approximately 72 million people suffer hypertension (Rosamond et al 2007). Affecting $\sim 30 \%$ of the US population $>20$ years-old, hypertension is one of the most common chronic medical conditions (Hajjar and Kotchen 2003; US National Center for Health Statistics 2005), and occurs almost twice as often in African-Americans as opposed to Caucasians (Burt et al 1995a, 1995b; Kearse et al 1998). Moreover, the incidence of hypertension increases with age (Dannenberg et al 1988; Borzecki et al 2003) and affects men at a slightly higher rate than women. Worldwide, hypertension may affect as many as 1 billion people and be responsible for $\sim 7.1$ million deaths per year (WHO 2002). Considering the prevalence of chronic hypertension, the management of patients with chronic hypertension undergoing surgery is of major clinical importance as these patients are at an increased risk of morbidity and mortality after surgery.

Hypertension is a frequent complication of cardiac surgery (Estafanous et al 1973; Viljoen et al 1976; Estafanous and Tarazi 1980). Perioperative hypertension occurs in $25 \%$ of hypertensive patients that undergo surgery (Prys-Roberts et al 1971; Goldman and Caldera 1979). During surgery, patients with and without preexisting hypertension are likely to develop blood pressure elevations and tachycardia during the induction of anesthesia (Erstad and Barletta 2000). Common predictors of perioperative hypertension are previous history of hypertension, especially a diastolic blood pressure greater than $110 \mathrm{~mm} \mathrm{Hg}$, and the type of surgery (Khuri et al 1995; Aronson et al 2002, 2007).

The Sixth Report of the Joint National Committee on Detection, Evaluation, and Treatment of High Blood Pressure (JNC6) (Chobanian et al 2003a; JNC 1997) identifies patients with a systolic blood pressure (BP) of $>180 \mathrm{~mm} \mathrm{Hg}$, or a diastolic that is $>110 \mathrm{~mm} \mathrm{Hg}$, as having a "hypertensive crisis". Hypertensive crisis is a term referring to either hypertensive emergencies or urgencies.

Hypertensive emergencies (ie, severe elevations in BP [ $>180 / 110 \mathrm{~mm} \mathrm{Hg}]$ complicated by evidence of impending or progressive target organ dysfunction) require immediate $\mathrm{BP}$ reduction to prevent or limit end organ damage. Examples of hypertensive 
emergencies include hypertensive encephalopathy, intracerebral hemorrhage, subarachnoid hemorrhage, and acute stroke; hypertension-induced acute renal dysfunction; and hypertension associated with unstable angina, acute myocardial infarction, acute coronary heart failure, and acute aortic dissection. Blood pressure should be reduced by $10 \%-15 \%$ (maximum of $20 \%$ ) in a controlled fashion within the first hour with a continued decrease towards 160/100 mm Hg over the next 2-6 hours as tolerated by the patient. A more rapid reduction is indicated in patients with aortic dissection.

Hypertensive urgencies are those situations associated with severe elevations in BP without progressive target organ dysfunction. Since end organ dysfunction is not present, hypertensive urgencies require less rapid reductions in pressure (ie, hours to days).

This article reviews the treatment options available for the management of hypertension in patients undergoing surgery. Due to the low incidence of hypertension in the pediatric population, this review is limited to the management of perioperative hypertension in adult patients. In this article, the term perioperative refers to the time of hospitalization directly related to a surgical procedure; and includes the preoperative, intraoperative, and postoperative (ie, 3 or 4 days post) periods.

\section{Incidence}

Perioperative hypertension often occurs in conjunction with one of the following events: during the induction of anesthesia; intraoperatively as associated with acute pain-induced sympathetic stimulation leading to vasoconstriction; in the early postanesthesia period, associated with pain induced sympathetic stimulation, hypothermia, hypoxia, or intravascular volume overload from excessive intraoperative fluid therapy; and in the 24 to 48 hours after postoperatively as fluid is mobilized from the extravascular space. In addition, blood pressure elevation secondary to discontinuation of long-term antihypertensive medication may occur postoperatively.

Hypertensive events occur most commonly with carotid surgery, abdominal aortic surgery, peripheral vascular procedures, and intraperitoneal, or intrathoracic, surgery (Goldman and Caldera 1979). At least $25 \%$ of patients undergoing noncardiac surgery have hypertension prior to their surgical procedure; elevated blood pressures (eg, systolic $\geq 170$ $\mathrm{mm} \mathrm{Hg}$, diastolic $\geq 110 \mathrm{~mm} \mathrm{Hg}$ ) have been associated with complications such as myocardial ischemia (Goldman et al 1977, 1997).

Data suggest that diastolic blood pressure of $\geq 110 \mathrm{~mm} \mathrm{Hg}$ is a preoperative marker of perioperative cardiac complications in patients with chronic hypertension (Goldman et al 1977). Patients with uncontrolled hypertension (ie, $>170 / 95$ mm Hg) undergoing carotid endarterectomies have been shown to have a significantly greater number of postoperative neurologic deficits $(\mathrm{p}<0.01)$ than patients with better control or normotensive patients (Towne and Bernhard 1980; Asiddao et al 1982). Therefore, patients on antihypertensive therapy should maintain compliance to their treatment regimen prior to surgery, including the morning of surgery, as it may contribute to fewer intraoperative blood pressure fluctuations (Goldberg and Larijani 1998; Chobanian et al 2003a).

\section{Preoperative hypertension}

Preoperative hypertension is frequently a hypertensive urgency, not an emergency, as it typically does not involve end organ damage and there usually adequate time to reduce the BP (Goldberg and Larijani 1998). A prospective, randomized multicenter study of more than 17,000 patients found that preoperative hypertension was associated with perioperative bradycardia, tachycardia, and hypertension (Forrest et al 1992). In a multivariate analysis of risk factors for perioperative complications in men who underwent noncardiac surgery, the presence of preoperative hypertension increased the odds ratio for postoperative death to 3.8 times that of normotensives (Browner et al 1992). In a case-controlled study of patients who died of a cardiac cause within 30 days of elective surgery, a preoperative history of hypertension was 4 times more likely than in an equal number of age-matched controls (Howell et al 1996).

Overall, the incidence of substantial intraoperative BP elevations (ie, systolic pressure $>160 \mathrm{~mm} \mathrm{Hg}$ ) in hypertensive patients undergoing noncardiac elective surgery appears to be $<10 \%$ with appropriate patient selection (ie, controlled hypertension) (Mangano et al 1990). Patients with higher preoperative BP undergoing elective surgery are at risk for increased perioperative hypertensive episodes, though the relationship of these episodes to clinically important complications has not been clearly demonstrated. Nonetheless, postponement of elective surgery is usually recommended until the BP is adequately controlled (Wolfsthal 1993). In patients with chronic hypertension, as long as the diastolic $\mathrm{BP}$ is $<110 \mathrm{~mm} \mathrm{Hg}$, it is not considered a reason to delay surgery.

When emergent surgery is necessary, excessive BP elevations should be lowered to limit or prevent possible aggravation of bleeding and damage to vital organs. Assuming there is no immediate threat to vital organ function, as may occur in patients with end organ disease secondary to 
chronic hypertension, such perioperative elevations in BP can generally be considered hypertensive urgencies (Mann and Atlas 1995).

Characterized by excessive sympathetic activity with rebound hypertension, clonidine withdrawal syndrome often resembles the hypertensive crisis of pheochromocytoma and may be misdiagnosed (Houston 1981; O’Connor 1981; Berge and Lanier 1991; Neusy and Lowenstein 1989). Symptoms of clonidine withdrawal syndrome are typically encountered 18 to 24 hours after sudden discontinuation of clonidine in patients taking more than $1.0 \mathrm{mg} /$ day. The simultaneous use of a nonselective beta-blocker may exacerbate clonidine withdrawal syndrome. Because there is no rapidly acting, parenteral form of this drug for use in patients who are unable to take oral medication, clonidine withdrawal syndrome is of particular concern in the perioperative period. Clonidine withdrawal syndrome may be corrected by reintroducing clonidine, either intramuscularly, or through treatment with methyldopa and labetalol. Preoperatively, the clonidine withdrawal syndrome can be prevented by converting the patient to a clonidine patch.

\section{Intraoperative and postoperative hypertension}

Acute elevations in blood pressure $(>20 \%)$ in the intraoperative period are typically considered hypertensive emergencies (Goldberg and Larijani 1998). Postoperative hypertension (arbitrarily defined as systolic BP $\geq 190 \mathrm{~mm} \mathrm{Hg}$ and/or diastolic BP $100 \mathrm{~mm} \mathrm{Hg}$ on 2 consecutive readings following surgery) (Plets 1989; Chobanian et al 2003b) may have significant adverse sequelae in both cardiac and noncardiac patients. Hypertension, and hypertensive crises, are very common in the early postoperative period and are related to increased sympathetic tone and vascular resistance (Roberts et al 1977; Alper and Calhoun 2002). Postoperative hypertension often begins 10-20 minutes after surgery and may last up to 4 hours (Towne and Bernhard 1980). If left untreated, patients are at increased risk for bleeding, cerebrovascular events, and myocardial infarctions (Goldberg and Larijani 1998).

In the surgical setting, acute severe hypertension may be encountered during cardiac surgery, major vascular surgery (eg, carotid endarterectomy, aortic surgery), neurosurgery, head and neck surgery, renal transplantation, and major trauma (ie, burns or head injury). The incidence of postoperative hypertensive crises varies depending on the population examined, being reported in 4 to $35 \%$ of patients shortly after the surgical procedure (Gal and Cooperman 1975; Prys-Rroberts 1984; Halpern et al 1990).

Patients with a personal or family history of cerebral hemorrhage are an example of a population at particular risk for complications related to these abrupt increases in blood pressure (Frohlich 1998). In addition, certain types of surgery (eg, coronary artery bypass surgery, aortic aneurysm repair, carotid endarterectomy) are associated with high rates of postoperative hypertension (McKillion and Dellinger 1997). Like other forms of hypertensive crises, a history of hypertension is commonly seen in patients with perioperative hypertension. The transient nature of postoperative hypertension, and the unique clinical factors present in the postoperative period, requires that this clinical syndrome be given particular attention.

\section{Treatment}

The approach to the treatment of perioperative hypertension is considerably different than the treatment of chronic hypertension (Levy 1993). The initial approach to treatment is prevention. Because many patients that develop postoperative hypertension do so as a result of withdrawal of their long-term antihypertensive regimen, this withdrawal should be minimized in the postoperative period. One preventive approach is to substitute long-acting preparations of the patient's long-term antihypertensive regimen starting, if possible, several days before surgery and to be given in the morning of the day of surgery.

In all cases, the possible causes of the patient's BP elevation should be considered, and it should be decided if the hypertension is a hypertensive emergency or urgency. In patients with a hypertensive emergency, it usually is necessary to treat with a parenteral antihypertensive agent. In the acute setting, the treatment goal is to decrease blood pressure by no more than 25\% (Chobanian et al 2003a). Advancing these guidelines, the authors believe the immediate goal of therapy in hypertensive emergencies to reduce diastolic BP by $10 \%$ to $15 \%$, or to approximately $110 \mathrm{~mm} \mathrm{Hg}$, over a period of 30 to 60 minutes. Sodium and volume depletion can be significant, and gentle volume expansion with IV saline solution will serve to restore organ perfusion and prevent an abrupt decline in BP when antihypertensive regimens are initiated. This goal decreases the likelihood of too-aggressive control, which may result in target organ hypoperfusion. Patients with chronic hypertension have cerebral and renal perfusion autoregulation shifted to a higher range. The brain and kidneys are particularly prone to hypoperfusion if blood pressure is lowered too rapidly. With the threat of organ 
injury diminished, attempts should be made to control blood pressure to baseline levels during 24 to 48 hours.

Postoperative hypertensive emergencies are uncommon after noncardiac surgery. Hypertension that occurs in relation to tracheal intubation, surgical incision, and emergence from anesthesia may be treated with short-acting $\beta$-blockers, angiotensin-converting enzyme (ACE) inhibitors, calcium channel blockers, or vasodilators (Weiss and Longnecker 1993). Postoperative situations that may result in a hypertensive emergency include rebound hypertension after withdrawal of antihypertensive medications, hypertension resulting in bleeding from vascular surgery suture lines, hypertension associated with head trauma, and hypertension caused by acute catecholamine excess (eg, pheochromocytoma). An initial approach is to reverse precipitating factors (pain, hypervolemia, hypoxia, hypercarbia, and hypothermia).

\section{Pharmacotherapy}

Pharmacotherapy for hypertensive crisis involves a wide variety of agents with different mechanisms of action and pharmacologic properties. The agent of choice in any particular situation will depend on the clinical presentation. The ideal agent for treatment of hypertensive emergencies should be rapid acting, predictable and easily titrated, safe, inexpensive, and convenient. Currently, many options are available (Table 1), each with distinct advantages and disadvantages. Preferred agents include labetalol, esmolol, nicardipine, and fenoldopam. Since an immediate reduction in blood pressure is desired, parenteral agents are discussed, with emphasis placed on newer agents. Clonidine and ACE inhibitors are long acting and poorly titratable; however, these agents may be useful in the management of hypertensive urgencies. ACE inhibitors are contraindicated in pregnancy (DiPette et al 1985; Hirschl et al 1997). A review of agents used in the management of perioperative hypertension, preferred conditions, and dosing is presented in Table 2 .

\section{Enalaprilat}

Enalaprilat, an ACE inhibitor available for intravenous (IV) administration has been studied extensively in the perioperative setting (Yates and Hunter 1988; Acampora et al 1989; Murphy et al 1989; Colson et al 1990; Boldt et al 1995; Heropoulos et al 1995; Tohmo and Karanko 1995). ACE inhibitors have shown efficacy in treating hypertension associated with congestive heart failure, essential hypertension, and prevention of worsening renal function in patients with diabetic, and nondiabetic, nephropathy. Enalaprilat has also been used preventatively in patients undergoing craniotomy (Kross et al 2000).

Table I Initial dosing of antihypertensive agents ${ }^{\mathrm{a}}$

\begin{tabular}{ll}
\hline Agent & Comment \\
\hline Enalaprilat & Intravenous intermittent: $0.625-1.25 \mathrm{mg}$ (lower dose if hyponatremia, possible volume depletion, concomitant diuretic \\
therapy, or renal failure) over $5 \mathrm{~min}$, then double at 4 - to 6 -h intervals until desired response, a single maximal dose \\
of $1.25-5 \mathrm{mg}$ (doses $\geq 1.25 \mathrm{mg}$ have not been of additional benefit, but doses $\leq 5 \mathrm{mg}$ have been given), toxicity, or a \\
cumulative dose of $20 \mathrm{mg}$ within a $24-\mathrm{h}$ period; contraindicated in $2 \mathrm{nd}$ and $3 \mathrm{rd}$ trimester of pregnancy \\
Intravenous infusion: $250-500 \mu \mathrm{g} / \mathrm{kg} / \mathrm{min}$ for I min, followed by a $50-100 \mu \mathrm{g} / \mathrm{kg} / \mathrm{min}$ infusion for $4 \mathrm{~min}$, then titrate \\
using same sequence (ie, with bolus before each rate increase) until desired response, a maximal dose of $300 \mu \mathrm{gg} / \mathrm{kg} /$
\end{tabular}

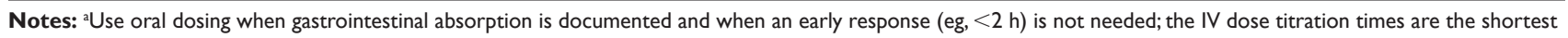
times recommended for BP control but not necessarily the best for a given patient; slower titrations are often warranted to preclude excessively rapid decreases in pressure, with subsequent perfusion complications. 
Table 2 Agents used in the management of perioperative hypertension, preferred conditions, and dosing

\begin{tabular}{|c|c|c|}
\hline Agent & Conditions & Dosing \\
\hline Enalaprilat & Congestive heart failure & 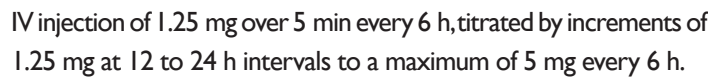 \\
\hline Esmolol & Acute myocardial ischemia ${ }^{a}$ & $\begin{array}{l}\text { Loading dose of } 500-1000 \mu \mathrm{g} / \mathrm{kg} \text { over I min, followed by an } \\
\text { infusion at } 25 \text { to } 50 \mu \mathrm{g} / \mathrm{kg} / \mathrm{min} \text {, which may be increased by } \\
25 \mu \mathrm{g} / \mathrm{kg} / \mathrm{min} \text { every } 10 \text { to } 20 \mathrm{~min} \text { until the desired response to } \\
\text { a maximum of } 300 \mu \mathrm{g} / \mathrm{kg} / \mathrm{min}\end{array}$ \\
\hline Fenoldopam & $\begin{array}{l}\text { Acute myocardial ischemiac } \\
\text { Acute pulmonary edema/diastolic dysfunction }{ }^{\mathrm{a}, \mathrm{b}} \\
\text { Acute ischemic stroke/intracerebral bleed Acute renal failure/ } \\
\text { microangiopathic anemia } \\
\text { Hypertensive encephalopathy } \\
\text { Sympathetic crisis }\end{array}$ & $\begin{array}{l}\text { An initial dose of } 0.1 \mu \mathrm{g} / \mathrm{kg} / \mathrm{min} \text {, titrated by increments of } 0.05 \\
\text { to } 0.1 \mu \mathrm{g} / \mathrm{kg} / \mathrm{min} \text { to a maximum of } 1.6 \mu \mathrm{g} / \mathrm{kg} / \mathrm{min} \text {. }\end{array}$ \\
\hline Labetalol & $\begin{array}{l}\text { Acute aortic dissection } \\
\text { Acute myocardial ischemia }^{\mathrm{a}} \\
\text { Acute ischemic stroke/intracerebral bleed } \\
\text { Eclampsia/Preeclampsia Hypertensive encephalopathy }\end{array}$ & $\begin{array}{l}\text { Initial bolus } 20 \mathrm{mg} \text {, followed by boluses of } 20-80 \mathrm{mg} \text { or an } \\
\text { infusion starting at I-2 mg/min and titrated up to until the } \\
\text { desired hypotensive effect is achieved is particularly effective. } \\
\text { Bolus injections of I to } 2 \mathrm{mg} / \mathrm{kg} \text { have been reported to produce } \\
\text { precipitous falls in BP and should therefore be avoided; maximum } \\
\text { cumulative dose of } 300 \mathrm{mg} \text { over } 24 \mathrm{~h}\end{array}$ \\
\hline Nicardipine & $\begin{array}{l}\text { Acute myocardial ischemiac } \\
\text { Acute renal failure/microangiopathic anemia } \\
\text { Acute ischemic stroke/intracerebral bleed Eclampsia/ } \\
\text { preeclampsia } \\
\text { Hypertensive encephalopathy } \\
\text { Sympathetic crisis/cocaine overdose }^{d}\end{array}$ & $\begin{array}{l}5 \mathrm{mg} / \mathrm{h} \text {; titrate to effect by increasing } 2.5 \mathrm{mg} / \mathrm{h} \text { every } 5 \mathrm{~min} \text { to } \\
\text { a maximum of } 15 \mathrm{mg} / \mathrm{h} \text {. }\end{array}$ \\
\hline
\end{tabular}

Notes: In combination with nitroglycerin (up to $200 \mu \mathrm{g} / \mathrm{min}$ ); In combination with a loop diuretic; May be added if pressure is controlled poorly with labetalol/esmolol alone; In combination with a benzodiazepine.

In general, enalaprilat is administered as an IV injection of $1.25 \mathrm{mg}$ over 5 minutes every 6 hours, titrated by increments of $1.25 \mathrm{mg}$ at 12 - to 24 -hour intervals up to a maximum of $5 \mathrm{mg}$ every 6 hours. Enalaprilat is effective in reducing the hypertensive response to endotracheal intubation during induction of anesthesia, but caution should be used when enalaprilat is used in conjunction with anesthetic agents (Hirschl et al 1995).

While the advantages of enalaprilat include bolus dosing versus continuous infusion, a lack of reflex tachycardia, and no effects on intracranial pressure (Schmidt et al 1990; Boldt et al 1995), a disadvantage is the delayed onset of action (15 minutes). In addition, enalaprilat does not reach peak effect for $\sim 1$ hour, and its duration of action is $\sim 6$ hours. The effective half-life for accumulation of enalaprilat is approximately 11 hours (Merck and Co. 2000). The relatively slow onset and long duration of action make enalaprilat a poor choice for use in a hypertensive emergency.

In addition, ACE inhibitors have the potential to cause acute renal failure, acute renal dysfunction, or hyperkalemia in patients in circulatory decompensated states or when mean arterial pressure is insufficient to support renal perfusion. Since surgical patients are at an increased risk for circulatory decompensation in the post operative period, ACE inhibitors should not be considered first-line agents in the treatment of acute perioperative hypertension.

\section{Esmolol}

Esmolol is an ultra-short-acting cardioselective, $\beta$-adrenergic blocking agent (Lowenthal et al 1985; Reynolds et al 1986; Gray 1988). Esmolol has been used successfully for hypertension in the perioperative period (Cucchiara et al 1986; Girard et al 1986; Newsome et al 1986; Gray et al 1987; Gibson et al 1988). The metabolism of esmolol is via rapid hydrolysis of ester linkages by red blood cell (RBC) esterases and is not dependant on renal or hepatic function. Esmolol is especially useful in severe postoperative hypertension (Gray et al 1985, 1987; Stumpf 1988; Platia et al 1989; Muzzi et al 1990; Smerling and Gersony 1990; Balser et al 1998) and is an ideal choice when cardiac output, heart rate, and BP are increased.

Esmolol has no direct vasodilatory actions. It decreases atrial pressure by decreasing heart rate and myocardial contractility and thus cardiac output. In general, the drug is administered as a $500-1000 \mu \mathrm{g} / \mathrm{kg}$ loading dose over 1 minute, followed by an infusion starting at $50 \mu \mathrm{g} / \mathrm{kg} / \mathrm{min}$ and increasing up to $300 \mu \mathrm{g} /$ $\mathrm{kg} / \mathrm{min}$ as necessary. Esmolol has a rapid onset (60 seconds) and short duration of action (10 to 20 minutes) (Lowenthal et al 1985; Reynolds et al 1986; Gray 1988). However, the need for 
bolus doses prior to incrementally increasing the maintenance infusion rate complicates the dosing of the drug. Additionally, because it is metabolized by RBC esterases, any condition that precipitates anemia will prolong its "short half-life".

Caution needs to be exercised when using esmolol in patients with chronic obstructive lung disease as it can precipitate bronchospasm. In addition, ACC/AHA guidelines conclude it may be contraindicated for patients already on $\beta$-blocker therapy, bradycardic patients, and decompensated heart failure patients as its use may compromise myocardial function (Hunt et al 2005).

\section{Labetalol}

Labetalol is a combined selective $\alpha 1$-adrenergic receptor blocker and nonselective $\beta$-adrenergic blocker given by IV bolus or continuous infusion. When given IV, the $\alpha$ - to $\beta$-blocking ratio of is 7:1 (Lund-Johansen 1984). Labetalol is metabolized by the liver to form an inactive glucuronide conjugate (Kanto et al 1981). This agent has been used in the setting of pregnancy-induced hypertensive crisis because little placental transfer occurs mainly due to the negligible lipid solubility of the drug (Pearce and Wallin 1994).

The hypotensive effect of labetalol begins within 2 to 5 minutes after its IV administration, The onset of action occurs within 2 to 5 minutes after its IV administration, reaching a peak at 5 to 15 minutes following administration, and lasting for about 2 to 4 hours (Kanto et al 1981; Goldberg et al 1990). The elimination half-life of labetalol is approximately 5.5 hours (Bedford Laboratories 2000). This variability makes labetalol extremely difficult to titrate as a continuous infusion.

Labetalol may be administered at a loading dose of $20 \mathrm{mg}$, followed by incremental doses of 20 to $80 \mathrm{mg}$ at repeated 10-minute intervals until the desired BP is achieved. Alternatively, after the initial loading dose, an infusion commencing at 1 to $2 \mathrm{mg} / \mathrm{min}$ and titrated up to until the desired hypotensive effect is achieved is particularly effective. Bolus injections of 1 to $2 \mathrm{mg} / \mathrm{kg}$ have been reported to produce precipitous falls in BP and should therefore be avoided (Rosei et al 1975).

Labetalol reduces the systemic vascular resistance without reducing total peripheral blood flow. In addition, the cerebral, renal, and coronary blood flows are maintained (Marx and Reid 1979; Wallin 1985; Pearce and Wallin 1994; Olsen et al 1995). Due to its $\beta$-blocking effects, the heart rate is either maintained or slightly reduced. Unlike pure $\beta$-adrenergic blocking agents that decrease cardiac output, labetalol maintains cardiac output (Pearce and Wallin 1994).

However, the use of labetalol following cardiac surgery has produced mixed results (Meretoja et al 1980; Morel et al
1982; Cruise et al 1989). Some studies (Meretoja et al 1980; Cruise et al 1989) noted a significant reduction in heart rate and blood pressure along with reductions in cardiac index. These differences in results may be attributable to the doses used and the study population differences, particularly regarding left ventricular function. Labetalol should be used with caution in patients with heart failure and avoided in patients with severe sinus bradycardia, heart block greater than first degree, and asthma.

\section{Clevidipine}

Clevidipine, a third generation dihydropyridine calcium channel blocker (CCB) developed for use in situations where stringent BP control is vital, is an ultrashort-acting selective arteriolar vasodilator (Ericsson et al 1999a; Bailey et al 2002; Rodríguez and Varon 2006). Clevidipine has a mean blood flow clearance of $0.105 \mathrm{~L} / \mathrm{kg} / \mathrm{min}$ and a volume of distribution of $0.51 \mathrm{~L} / \mathrm{kg}$. The half-life is approximately 2 minutes (Garcia and Vidt 1987).

Clevidipine acts by selectively inhibiting the influx of extracellular calcium through the L-type channel, relaxing smooth muscle of small arteries, and reducing peripheral vascular resistance (Ericsson et al 1999b). Clevidipine is rapidly metabolized by RBC esterases; therefore its metabolism is not affected by renal or hepatic function. Clevidipine reduces BP by a direct selective effect on arterioles, thereby reducing afterload without affecting cardiac filling pressures or causing reflex tachycardia (Nordlander et al 1996). Stroke volume and cardiac output usually increase. In addition to maintaining renal function and splanchnic blood flow, clevidipine has been shown to protect against ischemia/reperfusion injury in an animal model of myocardial ischemia (Segawa et al 2000, 2002; Stephens and Jandhyala 2002).

Several trials have shown clevidipine to be very effective in the control of preoperative and postoperative hypertension (Kieler-Jensen et al 2000; Powroznyk et al 2003). In a recent randomized, double-blind, placebo-controlled multicenter trial of 152 patients scheduled for cardiac surgery with current or recent hypertension were randomized to receive clevidipine or placebo preoperatively (Levy et al 2007). Patients received infusions of either clevidipine $\left(0.4-8.0 \mu \mathrm{g} \cdot \mathrm{kg}^{-1} \cdot \mathrm{min}^{-1}\right)$ or placebo (20\% lipid emulsion) for at least 30 minutes. Patients treated with clevidipine demonstrated a significantly higher rate of treatment success as compared to placebo treated group ( $92.5 \%$ vs $17.3 \%$ respectively, $\mathrm{P}<0.0001)$, and a significantly lower treatment failure rate than patients receiving placebo ( $7.5 \%$ vs $82.7 \%$ respectively, $\mathrm{P}<0.0001)$. Clevidipine achieved target blood pressures (systolic blood 
pressure reduced by $\geq 15 \%$ ) at a median of 6.0 minutes. Adverse events for each treatment group were similar.

While the role of this drug in hypertensive emergencies is yet to be determined, its profile makes it a potentially ideal drug for this indication. Clevidipine is not yet available for use in the United States beyond clinical trials. In the author's own experience, the use of clevidipine in acute hypertension in the emergency department setting is safe and provides a predictable blood pressure control. In addition, this drug is safe when infused for as long as 96 hours (Varon et al 2007).

\section{Nicardipine}

Nicardipine is a short-acting dihydropyridine calcium channel blocker (CCB) available for both IV and oral use. Likely due to its augmentation of coronary blood flow and ability to produce potent, more selective vasodilation in the coronary circulation than in the systemic vascular bed, IV nicardipine has been shown to reduce both cardiac and cerebral ischemia (Schillinger 1987); (Kaplan 1990).

The nicardipine dosage is independent of the patient's weight, with an initial infusion rate of $5 \mathrm{mg} / \mathrm{h}$, increasing by $2.5 \mathrm{mg} / \mathrm{h}$ every 5 minutes to a maximum of $15 \mathrm{mg} / \mathrm{h}$ until the desired BP reduction is achieved (Varon and Marik 2000). In the author's experiences much higher doses are commonly used $(30-45 \mathrm{mg} / \mathrm{hr})$. The onset of action of IV nicardipine is from 5 to 15 minutes, with duration of action of 4 to 6 hours.

A therapeutic benefit of nicardipine is that the agent has been demonstrated to increase both stroke volume and coronary blood flow with a favorable effect on myocardial oxygen balance (Lambert et al 1985, 1986, 1987; Schillinger 1987; Vincent et al 1997). This property is beneficial in patients with coronary artery disease and systolic heart failure. In addition, this agent has been recommended in the American Heart Association/American Stroke Association's guidelines for the treatment of ischemic stroke when diastolic blood pressure is $>120 \mathrm{~mm} \mathrm{Hg}$ or the systolic blood pressure is $>220 \mathrm{~mm} \mathrm{Hg}$ (Adams et al 2003, 2005; Broderick et al 2007).

\section{Fenoldopam}

Fenoldopam is a peripheral dopamine-1 (DA) receptor agonist administered by IV infusion for the treatment of severe hypertension. Fenoldopam is unique among the parenteral BP agents because it mediates peripheral vasodilation by acting on peripheral dopamine-1 receptors. Fenoldopam is rapidly and extensively metabolized by conjugation in the liver, without participation of cytochrome P-450 enzymes. Fenoldopam has been associated with an increase in urine output and occasionally an increase in creatinine clearance
(White and Halley 1989; Elliott et al 1990; Shusterman et al 1993) which makes fenoldopam use appealing in perioperative patients with or at risk for renal dysfunction.

The onset of action of fenoldopam is within 5 minutes, with the maximal response being achieved by 15 minutes (Weber et al 1988; White et al 1988; Munger et al 1990; Bodmann et al 1993). The elimination half-life of fenoldopam is $\sim 5$ minutes (Bedford Laboratories 2004), with a duration of action from 30 to 60 minutes. Blood pressure gradually returns to pretreatment values without rebound once the infusion is stopped (White et al 1988; Munger et al 1990; Bodmann et al 1993).

An initial starting dose of $0.1 \mu \mathrm{g} / \mathrm{kg} / \mathrm{min}$ is recommended for fenoldopam, titrated by increments of 0.05 to $0.1 \mu \mathrm{g} / \mathrm{kg} / \mathrm{min}$ to a maximum of $1.6 \mu \mathrm{g} / \mathrm{kg} / \mathrm{min}$.

While fenoldopam provides rapid blood pressure reduction, this change is often accompanied by reflex tachycardia (Bednarczyk et al 1989; Elliott et al 1990). Therefore, as with sodium nitroprusside, fenoldopam should be used with caution in patients at risk for myocardial ischemia. Additionally, fenoldopam causes dose-dependent increases in intraocular pressure, and its use should be avoided in patients at risk with intraocular hypertension and intracranial hypertension. In addition, fenoldopam is contained in a solution that contains a sodium metabisulfate, and patients with potential sulfite sensitivity may develop acute allergic reactions.

\section{Hydralazine}

Hydralazine is a direct-acting arteriolar vasodilator, often chosen as a first-line agent for critically ill patients with pregnancy-induced hypertension that produces a rapid blood pressure reduction, affecting diastolic more than systolic blood pressure.

The onset of action after either IM or IV administration is approximately 5 to 15 minutes followed by a progressive and often precipitous fall in BP that can last up to 12 hours (Schroeder 1951; Shepherd et al 1980), however; its maximum effect is usually noted between 10-80 minutes. Some anesthesiologists have found that 2 to $3 \mathrm{mg}$ boluses can allow for a more controlled reduction in blood pressure in the perioperative setting (Tietjen et al 1996).

Although the circulating half-life of hydralazine is only approximately 3 hours, the half-time of its effect on BP is approximately 10 hours (O'Malley et al 1975; Ludden et al 1980). Duration is dependent on hepatic acetylation and inactivation, making it difficult to titrate the drug to effect.

Its reduction of peripheral vascular resistance leads to a reflex tachycardia that can increase cardiac output. Therefore, 
hydralazine would not be a good choice in a patient with ischemic heart disease who may not tolerate the increased myocardial oxygen consumption associated with the cardiovascular effects (Powers et al 1998).

It should also be avoided in patients suspected of having a dissecting aneurysm. Because of the potent vasodilation of cerebral vessels caused by hydralazine, increased intracranial pressure may occur (James and Bedford 1982). Although the clinical importance of this action is controversial, hydralazine is best avoided in patients with intracranial processes (eg, head injury) in which increased intracranial pressure is an issue. In contrast, the increased renal blood flow attributable to hydralazine can be considered a potential advantage in patients with impaired renal function.

Because of the prolonged and unpredictable antihypertensive effects of hydralazine and the inability to effectively titrate its hypotensive effect, it is best avoided in the management of hypertensive crises.

\section{Nitroglycerin}

Nitroglycerin, an antianginal as well as antihypertensive drug, is a direct vasodilator of peripheral capacitance and resistance vessels. It is a greater venodilator than it is an arterial dilator. Nitroglycerin is more potent as a venodilator than it is an arterial dilator, but arterial dilation does occur at high doses (Bussmann et al 1992). By decreasing preload, nitroglycerin decreases left ventricular end diastolic volume and pressure, and reduces myocardial oxygen demand. Nitroglycerin also dilates coronary arteries, increasing the blood supply to ischemic regions of the heart.

Nitroglycerin reduces BP by reducing preload and cardiac output; undesirable effects in patients with compromised cerebral and renal perfusion. Intravenous nitroglycerin has an onset time of 2-5 minutes, duration of action of $\sim 10-20$ minutes, and is eliminated by hepatic metabolism in 1-4 minutes (Gerber and Nies 1990; Straka et al 1996) (Parke Davis Pharmaceuticals Ltd. 2000). It has pharmacokinetic properties similar to sodium nitroprusside. Hypotension and reflex tachycardia are common occurrences with nitroglycerin therapy, which are exacerbated by the volume depletion characteristic of hypertensive emergencies.

Nitroglycerin is not to be considered an acceptable primary therapy in the management of either hypertensive emergencies or urgencies (Varon and Marik, 2003), but may be a suitable adjunct therapy as it may have little or no efficacy when used alone and its antihypertensive action is caused by venodilation. Low-dose administration (approximately $60 \mathrm{mg} / \mathrm{min}$ ) may, however, be used as an adjunct to IV antihypertensive therapy in patients with hypertensive emergencies associated with acute coronary syndromes or acute pulmonary edema.

\section{Sodium nitroprusside}

Sodium nitroprusside is an arterial and venous vasodilator that decreases both afterload and preload (Robin and McCauley 1992; Friederich and Butterworth 1995). This results in a decrease in peripheral resistance without causing an increase in venous return.

Sodium nitroprusside is often considered a drug of choice for hypertensive emergencies, since it has an immediate onset of action and duration of effect of only 2 minutes. In patients with adequate circulating blood volume, nitroprusside has a predictable dose-response relationship, making it easy to titrate, and its efficacy has been widely documented in the perioperative setting (Kaplan and Jones 1979; Domenighetti and Perret 1982; van Wezel et al 1989; Halpern et al 1992; Leslie et al 1994).

Nitroprusside is a very potent agent, with an onset of action of seconds, a duration of action of 1 to 2 minutes, and a plasma half-life of 3 to 4 minutes (Friederich and Butterworth 1995). Due to its potency, rapidity of action, and the development of tachyphylaxis, the authors recommend intraarterial BP monitoring. In addition, sodium nitroprusside requires special handling to prevent its degradation by light. These factors limit the use of this drug (Tumlin et al 2000).

Nitroprusside decreases cerebral blood flow while increasing intracranial pressure (ICP), effects that are particularly detrimental in patients with hypertensive encephalopathy or following a cerebrovascular accident (Anile et al 1981; Griswold et al 1981; Kondo et al 1984; Hartmann et al 1989). In unanesthetized patient's sodium nitroprusside can increase ICP, causing cerebral perfusion pressure to drop (Turner et al 1977; Henriksen and Paulson 1982; Murphy and Sage 1988). These elevations in ICP may therefore be associated with cerebral ischemia despite the benefits of lower blood pressure. In patients with coronary artery disease, a significant reduction in coronary perfusion pressure (coronary steal) can occur (Mann et al 1978). In addition, the drug's vasodilatory adverse effects are frequently not predictable or preventable, and may involve organs other than the heart (eg, pulmonary shunting).

Another disadvantage of sodium nitroprusside involves accumulation of cyanide and thiocyanate. Sodium nitroprusside is nonenzymatically converted to cyanide, which 
is converted by the liver to thiocyanate which is 100 times less toxic than cyanide (Pasch et al 1983; Hall and Guest 1992). Thiocyanate is mainly eliminated through the kidneys. Cyanide removal therefore requires adequate liver function, renal function, and bioavailability of thiosulfate. Thus, nitroprusside may cause cytotoxicity due to the release of cyanide, with interference of cellular respiration (Izumi et al 1993; Niknahad and O'Brien 1996). In the authors' experience, patients can develop cyanide toxicity as early as 6-8 hours after initiation of the infusion.

Cyanide will also interfere with the vasodilator activity of sodium nitroprusside and lead to tachyphylaxis. This occurrence is more prevalent with high infusion rates $(>3 \mu \mathrm{g} / \mathrm{kg} / \mathrm{min})$ and prolonged administration ( $>72$ hours). Patients receiving high infusion rates for an extended duration may require periodic thiocyanate monitoring.

Data suggest that nitroprusside infusion rates $>4 \mu \mathrm{g} / \mathrm{kg} / \mathrm{min}$, for as little as 2 to 3 hours may lead to cyanide levels in the toxic range (Pasch et al 1983). Unfortunately, the development of toxicity cannot be predicted and may occur with lower doses (Cetnarowski and Conti 1986; Murphy and Sage 1988; Robin and McCauley 1992). Moreover, the recommended doses of nitroprusside of up to $10 \mu \mathrm{g} / \mathrm{kg} / \mathrm{min}$ results in cyanide formation at a far greater rate than human beings can detoxify. Sodium nitroprusside has also been demonstrated to cause cytotoxicity through the release of nitric oxide, with hydroxyl radical and peroxynitrite generation leading to lipid peroxidation (Niknahad and O'Brien 1996; Gobbel et al 1997; Nakamura et al 1997; Rauhala et al 1998).

Considering the potential for severe toxicity with nitroprusside, this drug should only be used when other IV antihypertensive agents are not available and then, only in specific clinical circumstances in patients with normal renal and hepatic function (Robin and McCauley 1992). An initial starting dose of $0.5 \mu \mathrm{g} / \mathrm{kg} / \mathrm{min}$; titrate as tolerated. The duration of treatment should be as short as possible, and the infusion rate should not be $>2 \mu \mathrm{g} / \mathrm{kg} / \mathrm{min}$. An infusion of thiosulfate should be used in patients receiving higher dosages (4-10 $\mu \mathrm{g} / \mathrm{kg} / \mathrm{min}$ ) of nitroprusside (Hall and Guest 1992).

\section{Conclusions}

Acute hypertension is common after major surgery and may be associated with an increased risk of serious cardiac and neurologic, complications. Hypertensive urgencies, and emergencies, occur in approximately $50 \%$ of patients during and immediately after cardiac surgery.
The goal of controlling perioperative hypertension is to protect organ function, and is currently recommended based on the assumption that the risk of complications will be reduced and outcomes improved. However, the treatment of acute elevations in BP (defined as an increase in systolic $\mathrm{BP}$, diastolic BP, or mean arterial pressure by $>20 \%$ over baseline in the perioperative period) is without a uniform approach. While attempts have been made to standardize the method to characterize the intraoperative hemodynamics, these methods still vary widely. Moreover, there is a lack of consensus concerning treatment thresholds and appropriate therapeutic targets, making absolute recommendations about treatment difficult. Nevertheless, perioperative hypertension requires careful management.

In general, the treatment goal should be based on the patient's preoperative BP. A conservative target would be approximately $10 \%$ above that baseline; however, a more aggressive approach to lowering BP may be warranted for patients at very high risk of bleeding or with severe heart failure who would benefit from afterload reduction. Careful monitoring of patient response to therapy, and adjustment of treatment, are paramount to safe and effective treatment of perioperative hypertension. After surgery, the clinician can safely transition the patient to an effective oral antihypertensive regimen to manage the long-term risks of hypertension and cardiovascular diseases.

When considering a potential course of treatment, the central question is how to balance the risks associated with hypertension versus the risk of end organ hypoperfusion that may accompany antihypertensive therapy. When treatment is necessary, therapy should be individualized for the patient. The choice of agent in specific cases should be determined by the clinical situation, the patient's characteristics, the setting of care, and the experience of the clinicians. A wide selection of available intravenous antihypertensive agents has provided the clinician with the ability to optimize therapy based on the specific needs of the situation and condition of the patient.

The ideal antihypertensive agent should provide immediate onset of action, a short to intermediate duration of action, be easy to titrate precisely, and have demonstrated safety and efficacy in the treatment of perioperative hypertension. Newer agents such as fenoldopam, nicardipine and clevidipine are valuable additions to the arena of effective pharmacological options such as enalaprilat, labetalol, nitroglycerin, esmolol, and hydralazine. Sodium nitroprusside should only be used when other IV antihypertensive agents are not available and then, only in specific clinical situations. 


\section{Acknowledgments}

The author would like to thank Richard Pistolese for his assistance in the preparation of this manuscript.

\section{Disclosure}

The authors have received honoraria for lectures from PDL Pharmaceuticals and The Medicines Company, and have served as consultants for The Medicines Company. There are no other conflicts of interest to report.

\section{References}

Acampora GA, Melendez JA, Keefe DL, et al. 1989. Intraoperative administration of the intravenous angiotensin-converting enzyme inhibitor, enalaprilat, in a patient with congestive heart failure. Anesth Analg, 69:833-9.

Adams H, Adams R, Del Zoppo G, et al. 2005. Guidelines for the early management of patients with ischemic stroke: 2005 guidelines update a scientific statement from the Stroke Council of the American Heart Association/American Stroke Association. Stroke, 36:916-23.

Adams HP Jr, Adams RJ, Brott T, et al. 2003. Guidelines for the early management of patients with ischemic stroke: A scientific statement from the Stroke Council of the American Stroke Association. Stroke, 34:1056-83.

Alper A, Calhoun D. 2002. Hypertensive emergencies. In: Antman EM ed. Cardiovascular therapeutics : a companion to Braunwald's Heart disease. 2nd ed. Philadelphia, PA: W.B. Saunders Co.

Anile C, Zanghi F, Bracali A, et al. 1981. Sodium nitroprusside and intracranial pressure. Acta Neurochir (Wien), 58:203-11.

Aronson S, Boisvert D, Lapp W. 2002. Isolated systolic hypertension is associated with adverse outcomes from coronary artery bypass grafting surgery. Anesth Analg, 94:1079-84.

Aronson S, Fontes ML, Miao Y, et al. 2007. Risk index for perioperative renal dysfunction/failure: critical dependence on pulse pressure hypertension. Circulation, 115:733-42.

Asiddao CB, Donegan JH, Whitesell RC, et al. 1982. Factors associated with perioperative complications during carotid endarterectomy. Anesth Analg, 61:631-7.

Bailey JM, Lu W, Levy JH, et al. 2002. Clevidipine in adult cardiac surgical patients: a dose-finding study. Anesthesiology, 96:1086-94.

Balser JR, Martinez EA, Winters BD, et al. 1998. Beta-adrenergic blockade accelerates conversion of postoperative supraventricular tachyarrhythmias. Anesthesiology, 89:1052-9.

Bedford Laboratories. 2004. Fenoldopam Mesylate Injection USP prescribing information [online]. Accessed on July 16, 2007. URL: http://www. bedfordlabs.com/products/inserts/fenoldopam_pi.pdf.

Bedford Laboratories. 2000. Labetolol HCL Injection USP prescribing information [online]. Accessed on July 16, 2007. URL:http://www. bedfordlabs.com/products/inserts/LBTL-P02.pdf.

Bednarczyk EM, White WB, Munger MA, et al. 1989. Comparative acute blood pressure reduction from intravenous fenoldopam mesylate versus sodium nitroprusside in severe systemic hypertension. Am J Cardiol, 63:993-6.

Berge KH, Lanier WL. 1991. Myocardial infarction accompanying acute clonidine withdrawal in a patient without a history of ischemic coronary artery disease. Anesth Analg, 72:259-61.

Bodmann KF, Troster S, Clemens R, et al. 1993. Hemodynamic profile of intravenous fenoldopam in patients with hypertensive crisis. Clin Investig, 72:60-4.

Boldt J, Schindler E, Wollbruck M, et al. 1995. Cardiorespiratory response of intravenous angiotensin-converting enzyme inhibitor enalaprilat in hypertensive cardiac surgery patients. J Cardiothorac Vasc Anesth, 9:44-9.

Borzecki AM, Wong AT, Hickey EC, et al. 2003. Hypertension control: how well are we doing? Arch Intern Med, 163:2705-11.
Broderick J, Connolly S, Feldmann E, et al. 2007. Guidelines for the management of spontaneous intracerebral hemorrhage in adults: 2007 update: a guideline from the American Heart Association/American Stroke Association Stroke Council, High Blood Pressure Research Council, and the Quality of Care and Outcomes in Research Interdisciplinary Working Group. Stroke, 38:2001-23.

Browner WS, Li J, Mangano DT. 1992. In-hospital and long-term mortality in male veterans following noncardiac surgery. The Study of Perioperative Ischemia Research Group. JAMA, 268:228-32.

Burt VL, Cutler JA, Higgins M, et al. 1995a. Trends in the prevalence, awareness, treatment, and control of hypertension in the adult US population. Data from the health examination surveys, 1960 to 1991. Hypertension, 26:60-9.

Burt VL, Whelton P, Roccella EJ, et al. 1995b. Prevalence of hypertension in the US adult population. Results from the Third National Health and Nutrition Examination Survey, 1988-1991. Hypertension, 25:305-13.

Bussmann WD, Kenedi P, von Mengden HJ, et al. 1992. Comparison of nitroglycerin with nifedipine in patients with hypertensive crisis or severe hypertension. Clin Investig, 70:1085-8.

Cetnarowski AB, Conti DR. 1986. Nitroprusside toxicity and low-dose infusion. Ann Intern Med, 104:895-6.

Chobanian AV, Bakris GL, Black HR, et al. 2003a. Seventh report of the Joint National Committee on Prevention, Detection, Evaluation, and Treatment of High Blood Pressure. Hypertension, 42:1206-52.

Chobanian AV, Bakris GL, Black HR, et al. 2003b. The Seventh Report of the Joint National Committee on Prevention, Detection, Evaluation, and Treatment of High Blood Pressure: the JNC 7 report. JAMA, 289:2560-72.

Colson P, Ribstein J, Mimran A, et al. 1990. Effect of angiotensin-converting enzyme inhibition on blood pressure and renal function during open heart surgery. Anesthesiology, 72:23-7.

Cruise CJ, Skrobik Y, Webster RE, et al. 1989. Intravenous labetalol versus sodium nitroprusside for treatment of hypertension postcoronary bypass surgery. Anesthesiology, 71:835-9.

Cucchiara RF, Benefiel DJ, Matteo RS, et al. 1986. Evaluation of esmolol in controlling increases in heart rate and blood pressure during endotracheal intubation in patients undergoing carotid endarterectomy. Anesthesiology, 65:528-31.

Dannenberg AL, Garrison RJ, Kannel WB. 1988. Incidence of hypertension in the Framingham Study. Am J Public Health, 78:676-9.

DiPette DJ, Ferraro JC, Evans RR, et al. 1985. Enalaprilat, an intravenous angiotensin-converting enzyme inhibitor, in hypertensive crises. Clin Pharmacol Ther, 38:199-204.

Domenighetti G, Perret C. 1982. Variable hemodynamic response to sodium nitroprusside in hypertensive crisis. Intensive Care Med, 8:187-91.

Elliott WJ, Weber RR, Nelson KS, et al. 1990. Renal and hemodynamic effects of intravenous fenoldopam versus nitroprusside in severe hypertension. Circulation, 81:970-7.

Ericsson H, Fakt C, Jolin-Mellgard A, et al. 1999a. Clinical and pharmacokinetic results with a new ultrashort-acting calcium antagonist, clevidipine, following gradually increasing intravenous doses to healthy volunteers. Br J Clin Pharmacol, 47:531-8.

Ericsson H, Tholander B, Regardh CG. 1999b. In vitro hydrolysis rate and protein binding of clevidipine, a new ultrashort-acting calcium antagonist metabolised by esterases, in different animal species and man. Eur J Pharm Sci, 8:29-37.

Erstad BL, Barletta JF. 2000. Treatment of hypertension in the perioperative patient. Ann Pharmacother, 34:66-79.

Estafanous FG, Tarazi RC. 1980. Systemic arterial hypertension associated with cardiac surgery. Am J Cardiol, 46:685-94.

Estafanous FG, Tarazi RC, Viljoen JF, et al. 1973. Systemic hypertension following myocardial revascularization. Am Heart J, 85:732-8.

Forrest JB, Rehder K, Cahalan MK, et al. 1992. Multicenter study of general anesthesia. III. Predictors of severe perioperative adverse outcomes. Anesthesiology, 76:3-15.

Friederich JA, Butterworth JF. 1995. Sodium nitroprusside: twenty years and counting. Anesth Analg, 81:152-62. 
Frohlich ED. 1998. Hypertension: evaluation and treatment. Baltimore, Md: Williams and Wilkins.

Gal TJ, Cooperman LH. 1975. Hypertension in the immediate postoperative period. Br J Anaesth, 47:70-4.

Garcia JY Jr, Vidt DG. 1987. Current management of hypertensive emergencies. Drugs, 34:63-78.

Gerber JG, Nies AS. 1990. Antihypertensive agents and the drug therapy of hypertension. In: Goodman LS, Gilman A, Gilman AG eds. Goodman and Gilman's the pharmacological basis of therapeutics. 8th ed. New York: Pergamon Pr.

Gibson BE, Black S, Maass L, et al. 1988. Esmolol for the control of hypertension after neurologic surgery. Clin Pharmacol Ther, 44:650-3.

Girard D, Shulman BJ, Thys DM, et al. 1986. The safety and efficacy of esmolol during myocardial revascularization. Anesthesiology, 65:157-64.

Gobbel GT, Chan TY, Chan PH. 1997. Nitric oxide- and superoxidemediated toxicity in cerebral endothelial cells. J Pharmacol Exp Ther, 282:1600-7.

Goldberg ME, Clark S, Joseph J, et al. 1990. Nicardipine versus placebo for the treatment of postoperative hypertension. Am Heart $J$, 119:446-50.

Goldberg ME, Larijani GE. 1998. Perioperative hypertension. Pharmacotherapy, 18:911-14.

Goldman L, Caldera DL. 1979. Risks of general anesthesia and elective operation in the hypertensive patient. Anesthesiology, 50:285-92.

Goldman L, Caldera DL, Nussbaum SR, et al. 1977. Multifactorial index of cardiac risk in noncardiac surgical procedures. $N$ Engl $J$ Med, 297:845-50.

Gray RJ. 1988. Managing critically ill patients with esmolol. An ultra shortacting beta-adrenergic blocker. Chest, 93:398-403.

Gray RJ, Bateman TM, Czer LS, et al. 1985. Use of esmolol in hypertension after cardiac surgery. Am J Cardiol, 56:49F-56F.

Gray RJ, Bateman TM, Czer LS, et al. 1987. Comparison of esmolol and nitroprusside for acute post-cardiac surgical hypertension. Am J Cardiol, 59:887-91.

Griswold WR, Reznik V, Mendoza SA. 1981. Nitroprusside-induced intracranial hypertension. JAMA, 246:2679-80.

Hajjar I, Kotchen TA. 2003. Trends in prevalence, awareness, treatment, and control of hypertension in the United States, 1988-2000. JAMA, 290:199-206.

Hall VA, Guest JM. 1992. Sodium nitroprusside-induced cyanide intoxication and prevention with sodium thiosulfate prophylaxis. Am J Crit Care, 1:19-25; quiz 26-7.

Halpern NA, Alicea M, Krakoff LR, et al. 1990. Postoperative hypertension: a prospective, placebo-controlled, randomized, double-blind trial, with intravenous nicardipine hydrochloride. Angiology, 41:992-1004.

Halpern NA, Goldberg M, Neely C, et al. 1992. Postoperative hypertension: a multicenter, prospective, randomized comparison between intravenous nicardipine and sodium nitroprusside. Crit Care Med, 20:1637-43.

Hartmann A, Buttinger C, Rommel T, et al. 1989. Alteration of intracranial pressure, cerebral blood flow, autoregulation and carbondioxide-reactivity by hypotensive agents in baboons with intracranial hypertension. Neurochirurgia (Stuttg), 32:37-43

Henriksen L, Paulson OB. 1982. The effects of sodium nitroprusside on cerebral blood flow and cerebral venous blood gases. II. Observations in awake man during successive blood pressure reduction. Eur J Clin Invest, 12:389-93.

Heropoulos M, Schieren H, Seltzer JL, et al. 1995. Intraoperative hemodynamic, renin, and catecholamine responses after prophylactic and intraoperative administration of intravenous enalaprilat. Anesth Analg, 80:583-90.

Hirschl MM, Binder M, Bur A, et al. 1995. Clinical evaluation of different doses of intravenous enalaprilat in patients with hypertensive crises. Arch Intern Med, 155:2217-23.

Hirschl MM, Binder M, Bur A, et al. 1997. Impact of the renin-angiotensinaldosterone system on blood pressure response to intravenous enalaprilat in patients with hypertensive crises. J Hum Hypertens, 11:177-83.
Houston MC. 1981. Abrupt cessation of treatment in hypertension: consideration of clinical features, mechanisms, prevention and management of the discontinuation syndrome. Am Heart J, 102:415-30.

Howell SJ, Sear YM, Yeates D, et al. 1996. Hypertension, admission blood pressure and perioperative cardiovascular risk. Anaesthesia, $51: 1000-4$.

Hunt SA, Abraham WT, Chin MH, et al. 2005. ACC/AHA 2005 Guideline Update for the Diagnosis and Management of Chronic Heart Failure in the Adult: a report of the American College of Cardiology/American Heart Association Task Force on Practice Guidelines (Writing Committee to Update the 2001 Guidelines for the Evaluation and Management of Heart Failure): developed in collaboration with the American College of Chest Physicians and the International Society for Heart and Lung Transplantation: endorsed by the Heart Rhythm Society. Circulation, 112:e154-235.

Izumi Y, Benz AM, Clifford DB, et al. 1993. Neurotoxic effects of sodium nitroprusside in rat hippocampal slices. Exp Neurol, 121:14-23.

James DJ, Bedford RF. 1982. Hydralazine for controlled hypotension during neurosurgical operations. Anesth Analg, 61:1016-19.

[JNC] Joint National Committee on Detection, Evaluation, and Treatment of High Blood Pressure. 1997. The sixth report of the Joint National Committee on prevention, detection, evaluation, and treatment of high blood pressure. Arch Intern Med, 157:2413-46.

[JNC] Joint National Committee on Detection, Evaluation, and Treatment of High Blood Pressure; National High Blood Pressure Education Program; Coordinating Committee. 2004. The Seventh Report of the Joint National Committee on Detection, Evaluation, and Treatment of High Blood Pressure, JNC7 (Complete Report). NIH Publication No. 04-5230. Bethesda, Md., National Heart, Lung, and Blood Institute, Health Information Center.

Kanto J, Allonen H, Kleimola T, et al. 1981. Pharmacokinetics of labetalol in healthy volunteers. Int J Clin Pharmacol Ther Toxicol, 19:41-4.

Kaplan JA. 1990. Clinical considerations for the use of intravenous nicardipine in the treatment of postoperative hypertension. Am Heart $J$, 119:443-6.

Kaplan JA, Jones EL. 1979. Vasodilator therapy during coronary artery surgery. Comparison of nitroglycerin and nitroprusside. J Thorac Cardiovasc Surg, 77:301-9.

Kearse LA Jr, Rosow C, Zaslavsky A, et al. 1998. Bispectral analysis of the electroencephalogram predicts conscious processing of information during propofol sedation and hypnosis. Anesthesiology, 88:25-34.

Khuri SF, Daley J, Henderson W, et al. 1995. The National Veterans Administration Surgical Risk Study: risk adjustment for the comparative assessment of the quality of surgical care. $J$ Am Coll Surg, 180:519-31.

Kieler-Jensen N, Jolin-Mellgard A, Nordlander M, et al. 2000. Coronary and systemic hemodynamic effects of clevidipine, an ultra-short-acting calcium antagonist, for treatment of hypertension after coronary artery surgery. Acta Anaesthesiol Scand, 44:186-93.

Kondo T, Brock M, Bach H. 1984. Effect of intra-arterial sodium nitroprusside on intracranial pressure and cerebral autoregulation. Jpn Heart J, 25:231-7.

Kross RA, Ferri E, Leung D, et al. 2000. A comparative study between a calcium channel blocker (Nicardipine) and a combined alpha-betablocker (Labetalol) for the control of emergence hypertension during craniotomy for tumor surgery. Anesth Analg, 91:904-9.

Lambert CR, Hill JA, Feldman RL, et al. 1986. Effects of nicardipine on left ventricular function and energetics in man. Int $J$ Cardiol, 10:237-50.

Lambert CR, Hill JA, Feldman RL, et al. 1987. Effects of nicardipine on exercise- and pacing-induced myocardial ischemia in angina pectoris. Am J Cardiol, 60:471-6.

Lambert CR, Hill JA, Nichols WW, et al. 1985. Coronary and systemic hemodynamic effects of nicardipine. Am J Cardiol, 55:652-6.

Leslie J, Brister N, Levy JH, et al. 1994. Treatment of postoperative hypertension after coronary artery bypass surgery. Double-blind comparison of intravenous isradipine and sodium nitroprusside. Circulation, 90: II256-61. 
Levy JH. 1993. The ideal agent for perioperative hypertension and potential cytoprotective effects. Acta Anaesthesiol Scand Suppl, 99:20-5.

Levy JH, Mancao MY, Gitter R, et al. 2007. Clevidipine effectively and rapidly controls blood pressure preoperatively in cardiac surgery patients: The results of the randomized, placebo-controlled efficacy study of clevidipine assessing its preoperative antihypertensive effect in cardiac surgery-1. Anesth Analg, 105:918-25.

Lowenthal DT, Porter RS, Saris SD, et al. 1985. Clinical pharmacology, pharmacodynamics and interactions with esmolol. Am J Cardiol, $56: 14 \mathrm{~F}-18 \mathrm{~F}$.

Ludden TM, Shepherd AM, McNay JL, et al. 1980. Hydralazine kinetics in hypertensive patients after intravenous administration. Clin Pharmacol Ther, 28:736-42.

Lund-Johansen P. 1984. Pharmacology of combined alpha-beta-blockade. II. Haemodynamic effects of labetalol. Drugs, 28(Suppl 2):35-50.

Mangano DT, Browner WS, Hollenberg M, et al. 1990. Association of perioperative myocardial ischemia with cardiac morbidity and mortality in men undergoing noncardiac surgery. The Study of Perioperative Ischemia Research Group. N Engl J Med, 323:1781-8.

Mann SJ, Atlas SA. 1995. Hypertensive emergencies. In: Laragh JH, Brenner BM (Eds). Hypertension: pathophysiology, diagnosis, and management. 2nd ed. New York: Raven Pr.

Mann T, Cohn PF, Holman LB, et al. 1978. Effect of nitroprusside on regional myocardial blood flow in coronary artery disease. Results in 25 patients and comparison with nitroglycerin. Circulation, 57:732-8.

Marx PG, Reid DS. 1979. Labetalol infusion in acute myocardial infarction with systemic hypertension. Br J Clin Pharmacol, 8:233S-238S.

McKillion PC, Dellinger RP. 1997. Hypertensive emergencies and urgencies. In: Civetta JM, Taylor RW, Kirby RR (Eds). Critical care. 3rd ed. Philadelphia: Lippincott-Raven.

Merck and Co. 2000. Vasotec ${ }^{\circledR}$ I.V (enalaprilat) prescribing information [online]. Accessed on July 16, 2007. URL: http://www.fda.gov/cder/ foi/label/2001/19309s23lbl.pdf.

Meretoja OA, Allonen H, Arola M, et al. 1980. Combined alpha- and betablockade with labetalol in post-open heart surgery hypertension. Reversal of hemodynamic deterioration with glucagon. Chest, 78:810-15.

Morel DR, Forster A, Suter PM. 1982. I.V. labetalol in the treatment of hypertension following coronary-artery surgery. Br J Anaesth, 54:1191-6.

Munger MA, Rutherford WF, Anderson L, et al. 1990. Assessment of intravenous fenoldopam mesylate in the management of severe systemic hypertension. Crit Care Med, 18:502-4.

Murphy JD, Vaughan RS, Rosen M. 1989. Intravenous enalaprilat and autonomic reflexes. The effects of enalaprilat on the cardiovascular responses to postural changes and tracheal intubation. Anaesthesia, 44:816-21.

Murphy JM, Sage JI. 1988. Trimethaphan or nitroprusside in the setting of intracranial hypertension. Clin Neuropharmacol, 11:436-42.

Muzzi DA, Black S, Losasso TJ, et al. 1990. Labetalol and esmolol in the control of hypertension after intracranial surgery. Anesth Analg, 70:68-71.

Nakamura Y, Yasuda M, Fujimori H, et al. 1997. Cytotoxic effect of sodium nitroprusside on PC12 cells. Chemosphere, 34:317-24.

Neusy AJ, Lowenstein J. 1989. Blood pressure and blood pressure variability following withdrawal of propranolol and clonidine. J Clin Pharmacol, 29:18-24.

Newsome LR, Roth JV, Hug CC Jr, et al. 1986. Esmolol attenuates hemodynamic responses during fentanyl-pancuronium anesthesia for aortocoronary bypass surgery. Anesth Analg, 65:451-6.

Niknahad H, O'Brien PJ. 1996. Involvement of nitric oxide in nitroprussideinduced hepatocyte cytotoxicity. Biochem Pharmacol, 51:1031-9.

Nordlander M, Bjorkman JA, Regard HC, et al. 1996. Pharmacokinetics and hemodynamic effects of an ultrashort-acting calcium antagonist. Br J Anaesth, 76:A24.

O'Connor DE. 1981. Accelerated acute clonidine withdrawal syndrome during coronary artery bypass surgery. A case report. Br J Anaesth, $53: 431-3$.
O’Malley K, Segal JL, Israili ZH, et al. 1975. Duration of hydralazine action in hypertension. Clin Pharmacol Ther, 18:581-6.

Olsen KS, Svendsen LB, Larsen FS, et al. 1995. Effect of labetalol on cerebral blood flow, oxygen metabolism and autoregulation in healthy humans. Br J Anaesth, 75:51-4.

Parke Davis Pharmaceuticals Ltd. 2000. Nitrostat ${ }^{\mathbb{}}$ (nitroglycerin tablets, USP) prescribing information [online]. Accessed on July 16, 2007. URL: http://www.pfizer.com/pfizer/download/uspi_nitrostat.pdf.

Pasch T, Schulz V, Hoppelshauser G. 1983. Nitroprusside-induced formation of cyanide and its detoxication with thiosulfate during deliberate hypotension. J Cardiovasc Pharmacol, 5:77-85.

Pearce CJ, Wallin JD. 1994. Labetalol and other agents that block both alpha- and beta-adrenergic receptors. Cleve Clin J Med, 61:59-69; quiz $80-2$

Platia EV, Michelson EL, Porterfield JK, et al. 1989. Esmolol versus verapamil in the acute treatment of atrial fibrillation or atrial flutter. $A m J$ Cardiol, 63:925-9.

Plets C. 1989. Arterial hypertension in neurosurgical emergencies. Am J Cardiol, 63:40C-42C.

Powers DR, Papadakos PJ, Wallin JD. 1998. Parenteral hydralazine revisited. J Emerg Med, 16:191-6.

Powroznyk AV, Vuylsteke A, Naughton C, et al. 2003. Comparison of clevidipine with sodium nitroprusside in the control of blood pressure after coronary artery surgery. Eur J Anaesthesiol, 20:697-703.

Prys-Roberts C, Greene LT, Meloche R, et al. 1971. Studies of anaesthesia in relation to hypertension. II. Haemodynamic consequences of induction and endotracheal intubation. Br J Anaesth, 43:531-47.

Prys-Rroberts C. 1984. Anaesthesia and hypertension. Br J Anaesth, 56:711-24.

Rauhala P, Khaldi A, Mohanakumar KP, et al. 1998. Apparent role of hydroxyl radicals in oxidative brain injury induced by sodium nitroprusside. Free Radic Biol Med, 24:1065-73.

Reynolds RD, Gorczynski RJ, Quon CY. 1986. Pharmacology and pharmacokinetics of esmolol. J Clin Pharmacol, 26(Suppl A):A3-A14.

Roberts AJ, Niarchos AP, Subramanian VA, et al. 1977. Systemic hypertension associated with coronary artery bypass surgery. Predisposing factors, hemodynamic characteristics, humoral profile, and treatment. J Thorac Cardiovasc Surg, 74:846-59.

Robin ED, McCauley R. 1992. Nitroprusside-related cyanide poisoning. Time (long past due) for urgent, effective interventions. Chest, 102:1842-5.

Rodríguez G, Varon J. 2006. Clevidipine: A Unique Agent for the Critical Care Practitioner. Crit Care and Shock, 9:37-41.

Rosamond W, Flegal K, Friday G, et al. 2007. Heart disease and stroke statistics - 2007 update: a report from the American Heart Association Statistics Committee and Stroke Statistics Subcommittee. Circulation, 115:e69-171.

Rosei EA, Trust PM, Brown JJ, et al. 1975. Letter: Intravenous labetalol in severe hypertension. Lancet, 2:1093-4.

Schillinger D. 1987. Nifedipine in hypertensive emergencies: a prospective study. J Emerg Med, 5:463-73.

Schmidt JF, Andersen AR, Paulson OB, et al. 1990. Angiotensin-converting enzyme inhibition, $\mathrm{CBF}$ autoregulation, and ICP in patients with normal-pressure hydrocephalus. Acta Neurochir (Wien), 106:9-12.

Schroeder HA. 1951. Effects on hypertension of sulfhydryl and hydrazine compounds. J Clin Invest, 30:672-73.

Segawa D, Sjoquist PO, Wang QD, et al. 2000. Calcium antagonist protects the myocardium from reperfusion injury by interfering with mechanisms directly related to reperfusion: an experimental study with the ultrashort-acting calcium antagonist clevidipine. J Cardiovasc Pharmacol, 36:338-43.

Segawa D, Sjoquist PO, Wang QD, et al. 2002. Time-dependent cardioprotection with calcium antagonism and experimental studies with clevidipine in ischemic-reperfused pig hearts: part II. J Cardiovasc Pharmacol, 40:339-45.

Shepherd AM, Ludden TM, McNay JL, et al. 1980. Hydralazine kinetics after single and repeated oral doses. Clin Pharmacol Ther, 28:804-11. 
Shusterman NH, Elliott WJ, White WB. 1993. Fenoldopam, but not nitroprusside, improves renal function in severely hypertensive patients with impaired renal function. Am J Med, 95:161-8.

Smerling A, Gersony WM. 1990. Esmolol for severe hypertension following repair of aortic coarctation. Crit Care Med, 18:1288-90.

Stephens CT, Jandhyala BS. 2002. Effects of fenoldopam, a dopamine D-1 agonist, and clevidipine, a calcium channel antagonist, in acute renal failure in anesthetized rats. Clin Exp Hypertens, 24:301-13.

Straka RJ, Lohr B, Borchardt-Phelps P, et al. 1996. Antihypertensive Agents. In: Irwin RS, Cerra FB, Rippe JM eds. Intensive care medicine. 3rd ed. Boston: Little, Brown.

Stumpf JL. 1988. Drug therapy of hypertensive crises. Clin Pharm, 7:582-91.

Tietjen CS, Hurn PD, Ulatowski JA, et al. 1996. Treatment modalities for hypertensive patients with intracranial pathology: options and risks. Crit Care Med, 24:311-22.

Tohmo H, Karanko M. 1995. Enalaprilat controls postoperative hypertension while maintaining cardiac function and systemic oxygenation after neurosurgery. Intensive Care Med, 21:651-6.

Towne JB, Bernhard VM. 1980. The relationship of postoperative hypertension to complications following carotid endarterectomy. Surgery, 88:575-80

Tumlin JA, Dunbar LM, Oparil S, et al. 2000. Fenoldopam, a dopamine agonist, for hypertensive emergency: a multicenter randomized trial. Fenoldopam Study Group. Acad Emerg Med, 7:653-62.

Turner JM, Powell D, Gibson RM, et al. 1977. Intracranial pressure changes in neurosurgical patients during hypotension induced with sodium nitroprusside or trimetaphan. Br J Anaesth, 49:419-25.

US National Center for Health Statistics. 2005. Health, United States, 2005 with chartbook on trends in the health of Americans with special feature on drugs. Hyattsville, Md, Washington, DC, Dept. of Health and Human Services, Centers for Disease Control and Prevention.

van Wezel HB, Koolen JJ, Visser CA, et al. 1989. The efficacy of nicardipine and nitroprusside in preventing poststernotomy hypertension. $J$ Cardiothorac Anesth, 3:700-6.
Varon J, Marik PE. 2000. The diagnosis and management of hypertensive crises. Chest, 118:214-27.

Varon J, Marik PE. 2003. Clinical review: the management of hypertensive crises. Crit Care, 7:374-84.

Varon J, Peacock W, Garrison N, et al. 2007. Prolonged infusion of clevidipine results in safe and predictable blood pressure control in patients with acute severe hypertension. Chest, 132:4775.

Viljoen JF, Estafanous FG, Tarazi RC. 1976. Acute hypertension immediately after coronary artery surgery. $J$ Thorac Cardiovasc Surg, 71:548-50.

Vincent JL, Berlot G, Preiser JC, et al. 1997. Intravenous nicardipine in the treatment of postoperative arterial hypertension. $J$ Cardiothorac Vasc Anesth, 11:160-4.

Wallin JD. 1985. Adrenoreceptors and renal function. J Clin Hypertens, $1: 171-8$.

Weber RR, McCoy CE, Ziemniak JA, et al. 1988. Pharmacokinetic and pharmacodynamic properties of intravenous fenoldopam, a dopamine 1-receptor agonist, in hypertensive patients. Br J Clin Pharmacol, 25:17-21.

Weiss SJ, Longnecker DE. 1993. Perioperative hypertension: an overview. Coron Artery Dis, 4:401-6.

[WHO] World Health Organization. 2002. Reducing risks, promoting healthy life. The world health report. Geneva, World Health Organization

White WB, Halley SE. 1989. Comparative renal effects of intravenous administration of fenoldopam mesylate and sodium nitroprusside in patients with severe hypertension. Arch Intern Med, 149:870-4.

White WB, Radford MJ, Gonzalez FM, et al. 1988. Selective dopamine-1 agonist therapy in severe hypertension: effects of intravenous fenoldopam. J Am Coll Cardiol, 11:1118-23.

Wolfsthal SD. 1993. Is blood pressure control necessary before surgery? Med Clin North Am, 77:349-63.

Yates AP, Hunter DN. 1988. Anaesthesia and angiotensin-converting enzyme inhibitors. The effect of enalapril on peri-operative cardiovascular stability. Anaesthesia, 43:935-8. 
